\title{
5
}

\section{La Financiación en las Cooperativas de Centroamérica ${ }^{1}$}

\author{
Dra. Roxana Sánchez Boza
}

\begin{abstract}
Sumario: 1. La legislación cooperativa en los países de la región.-2. Naturaleza de las Cooperativas.-3. Recursos financieros de las Cooperativas.-4. Propiedad cooperativa colectiva y propiedad cooperativa individual.- 5 . Límites de acceso de recursos financieros. El caso de las operaciones con terceros.-6. Beneficios, exenciones: impuestos, tasas, Impuesto de la Renta a las Cooperativas de Centroamérica.-7. Características de las aportaciones sociales.-8. Capitalización de excedentes e intereses.-9. Aportaciones de los socios que no entran a forar parte del capital social. Fondos internos de las Cooperativas.-10. La distribución de excedentes como origen de las reservas cooperativas.-11. Las otras reservas obligatorias: reserva de educación y bienestar social.-12. Irrepartibilidad de las reservas.-13. Revaloración de activos.14. Otras fuentes de financiamiento interno de las Cooperativas en Centroamérica. 14.1. Apoyo estatal para recuperar dineros de asociados trabajadores en dependencias públicas. 14.2. Creación de fondos para sostener entes cooperativos de integración y ayuda a Cooperativas. 14.3. Privilegio de cobro a favor de la Cooperativa. 14.4. Formas de financiamiento a traves de la integración cooperativa. 14.5. Crédito a favor de las Cooperativas.-A modo de conclusión.-Bibliografía básica.
\end{abstract}

\section{La legislación cooperativa en los países de la región}

Los países centroamericanos han venido padeciendo muchos problemas. Sean embates naturales o bien, la falta de gobiernos democráticos, tales países han tenido un atraso en su desarrollo, lo cual incide en la existencia de gran cantidad de personas pobres y de economía esencialmente agrícola.

Con la excepción de Costa Rica, con una larga tradición democrática, bajo el sistema presidencialista; el resto de países de Centroamérica,

1 Para mayor facilidad de consulta, remitimos a los lectores y las lectoras a la cita de legislación al final del artículo. 
casi están estrenando el sistema democrático, siendo el más reciente, Nicaragua.

En cuanto a la legislación cooperativa, encontramos que las leyes de cada país tienen un origen y contenido similar. No hay necesidad de la armonización porque ya sigue un esquema similar.

El tema de la financiación de las cooperativas necesariamente debe iniciar con su relación con el patrimonio y dentro de éste el fondo de capital de la empresa cooperativa. Que nos lleva a encontrar la debilidad persistente de los recursos financieros de las cooperativas, dado que sus características se centran en su variabilidad, pese a que se indica en la mayoría de las legislaciones que su monto es ilimitado.

La falta de límite en el extremo inferior del capital, no ha sido un beneficio para los entes cooperativos, porque más bien si debemos hablar de financiamiento de las cooperativas, tenemos que dividirlo, al menos, en financiamiento interno y financiamiento externo. Es en el financiamiento interno donde encontramos el capital cooperativo, que generalmente es escaso, como veremos más adelante. Para F. Perroux es la enfermedad infantil o sea la debilidad de ahorro de sus miembros, citado Arazandi. ${ }^{2}$

Eso sí, no siempre el panorama del financiamiento cooperativo es oscuro, por la debilidad apuntada, pues, en algunos casos, los Estados de tipo proteccionista, han establecido varias exenciones en beneficio de las cooperativas y como forma de incentivar su desarrollo y funcionamiento. ${ }^{3}$

\section{Naturaleza de las Cooperativas}

Ubicamos nuestro primer acercamiento a las cooperativas de la región centroamericana y la legislación especial que les atañe, en cuanto a la definición que los Estados centroamericanos realizan de las mismas y de su función. En general, en todos esos países existen normas programáticas que tienden a reconocer la función social que realizan las cooperativas y las hace merecedoras de su consideración dentro

\footnotetext{
2 P. 361.

3 Esto porque en algunos países las exenciones de pago de impuesto permanecen a favor de las cooperativas, durante todo el tiempo de su existencia.
} 
de la utilidad pública que cumplen dentro del desarrollo socio-económico y político de cada país.

Dentro de las leyes más recientes encontramos la panameña, Ley N. 17 de mayo de 1997, en donde se establecen una serie de tareas que deben cumplir las cooperativas, tales como:

- constituir un sistema eficaz para contribuir al desarrollo económico;

- contribuir al fortalecimiento de la democracia, a la equitativa distribución de la riqueza y del ingreso, a la racionalización de las actividades económicas y a facilitar, tarifas, tasas costos y precios en favor de la comunidad en general —artículo 2-.

Las tareas mencionadas enmarcan a las cooperativas como entes de derecho privado, en los cuales la sociedad, vía decisión estatal, refleja una política de traslado de sus propias funciones y obligaciones en organizaciones socio-económicas, que actualmente están incluidas como parte de la sociedad civil. Y que permite en muchos casos a los Estados, dejar de prestar atención en todo o en parte, a muchos de los requerimientos del desarrollo de los sectores populares que forman parte de estas organizaciones.

En general, la decisión política se plasma en la normativa inicial, en la parte de las Disposiciones generales, de las leyes cooperativas. A modo de ejemplo, transcribimos en forma completa el artículo segundo, con el fin de ofrecer el panorama completo de la toma de posición en la normativa mencionada:

Artículo 2. Las Cooperativas constituyen asociaciones de utilidad pública, de interés social y de derecho privado; y el ejercicio del cooperativismo se considera un sistema eficaz para contribuir al desarrollo económico. Al fortalecimiento de la democracia a la equitativa distribución de la riqueza y del ingreso a la racionalización de las actividades económicas y a facilitar, tarifas, tasas costos y precios en favor de la comunidad en general.

El Estado fomentará las cooperativas mediante la adecuada asistencia técnica y financiera, y las fiscalizará. Para asegurar el libre desenvolvimiento y desarrollo de las cooperativas. El Estado les garantiza autonomía jurídica y funcionamiento democrático.

En el artículo segundo del Decreto N. 82-78 de LEY GENERAL DE COOPERATIVAS nos encontramos con una definición más moderna de la naturaleza de las cooperativas, pues el artículo segundo indica que son empresas económicas. 
Costa Rica también define las cooperativas como entes de conveniencia pública e interés social con la carga de contribuir al desarrollo económico, social, cultural y democrático de los habitantes del país, según artículo primero de la ley de Asociaciones cooperativas y creación del Instituto Nacional de Fomento cooperativo N. 4179 de 22 de agosto de 1968 y sus reformas.

Honduras en su artículo séptimo incisos d) y e) establece las condiciones para constitución y funcionamiento de las cooperativas como entes nacidos para contribuir al desarrollo nacional. Esto se encuentra cuando la ley cooperativa considera que el patrimonio cooperativo se puede beneficiar si las cooperativas contribuyen al incremento de la producción y la productividad, el estímulo del ahorro, la inversión, el trabajo y la sana utilización del crédito. ${ }^{4}$

La norma programática es completada en el desarrollo de las legislaciones, bajo nuestro estudio, con una serie de normas que ofrecen medios a las cooperativas para lograr los objetivos trazados en sus capítulos de disposiciones generales. Como veremos esos caminos están deslindados por medio de incentivos o exoneraciones fiscales, o bien, con el establecimiento de mecanismos de compensación de deudas de las cooperativas y sus asociados(as); así como la existencia de reservas irrepartibles, las cuales se nutren de múltiples fondos provenientes de la actividad de las cooperativas con terceros y de los excedentes no gozados por los miembros de las mismas.

Un ejemplo lo encontramos en NICARAGUA, país donde se establece la compensación mediante los excedentes de las deudas de los cooperativistas provenientes del crédito individual, por medio de la siguiente norma:

Artículo 57. Cuando el cooperado adeude parte de las aportaciones que haya suscrito, los excedentes e intereses que le correspondan por los aportes de capital que hubiere pagado serán aplicados, hasta donde alcancen, a cubrir el saldo exigible.

Mientras que en el siguiente artículo 58 se incluyen los aportes y los depósitos como dineros que servirán a compensar deudas de un cooperado con su cooperativa, a la vez que se establece un orden preferencial, a favor de la cooperativa, frente a los acreedores personales

4 Ley hondureña, Decreto 65-87. 
de los cooperados. ${ }^{5}$ Artículo 59. Los patrones del sector público y privado están obligados a efectuar las deducciones de los sueldos o salarios que sus empleados o trabajadores autoricen por escrito para aplicarse al pago de ahorros, aportaciones, préstamos, intereses o cualquiera otra obligación que como cooperados contraigan, hasta la completa cancelación de las mismas, todo sin perjuicio de las disposiciones que regulen en el salario mínimo. Las sumas deducidas serán entregadas a las respectivas cooperativas de acuerdo a que disponga el Reglamento.

También pueden formar parte del patrimonio cooperativo algunos derechos de contratación preferencial, o bien, el reconocimiento del goce de ciertos derechos de usufructo para ciertos tipos de cooperativas, como el caso de las cooperativas de autogestión en Costa Rica, como lo veremos más adelante.

\section{Recursos financieros de las Cooperativas}

Consideramos oportuno indicar que ya existe un gran desarrollo acerca de los conceptos relacionados con este aporte. Nuestra contribución será ofrecer, en forma parcial, la referencia de la forma en que está tratado el tema del financiamiento en las cooperativas, pues una de las deudas más grandes que tenemos en nuestros estudios, es la falta de comprobación de la efectividad de las normas, vía el estudio de la aplicación real del Derecho cooperativo, en cada uno de los países objeto de nuestro.

Con base en lo anterior, nos apoyamos en Dionisio Arazandi, quien nos guía acerca del tema cuando expresa que: «El capital propio en toda empresa puede tener un doble origen: las aportaciones de los socios y los superávit económicos convertidos. Por ello también en la empresa cooperativa, la propiedad de la misma viene constituida por un fondo compuesto por las aportaciones de los socios y las reservas colectivas. ${ }^{6}$

5 Dice el segundo párrafo del artículo 58: «Los acreedores personales de los cooperados, no podrán embargar más que los excedentes que correspondan a éstos una vez cubiertas las deudas a favor de la cooperativa, o la parte del capital a que tengan derecho en caso de liquidación.»

6 En Cooperativismo industrial como sistema, empresa y experiencia, Universidad de Deusto, Bilbao, España, 1976, p. 364. 
De la forma en que se trate la propiedad cooperativa podemos encontrar la existencia de diferentes fuentes de financiamiento para las cooperativas. Básicamente tales fuentes se dividen en internas y externas. Las fuentes internas dan origen a un esquema integrado por la propiedad cooperativa colectiva y la propiedad cooperativa individual. La primera caracterizada por la indisponibilidad de sus elementos, en forma individual, por parte de los cooperativistas. La segunda, es una propiedad limitada, dado que hasta tanto no se apliquen los montos de reservas y contribuciones solidarias, establecidas en las leyes cooperativas, el socio o la socia, no pueden acceder a su goce y disposición, con los atributos de la propiedad,

\section{Propiedad cooperativa colectiva y propiedad cooperativa individual}

Cuando consideramos el financiamiento de las cooperativas el tema de la propiedad cooperativa es importante, sobre todo, en cuanto a las fuentes internas, porque el disfrute y disposición de tales recursos encuentra diferentes límites de tipo legal, derivados del desarrollo doctrinario del cooperativismo.

El patrimonio de las cooperativas es privado, pero indisponible en forma individual por los socios(as), forman parte de éste, las reservas legales o voluntarias — creadas por la asamblea de socios-, las donaciones y cualquier otra fuente de ingreso que genere la cooperativa y sea lícito. El patrimonio lo enmarcamos dentro del concepto de propiedad cooperativa colectiva, con indivisión forzosa, instrumento del desarrollo de la cooperativa, tanto económico como social.

La integración del patrimonio cooperativo tiene diferentes fuentes, y su origen está establecido en las legislaciones cooperativas centroamericanas, en diferente forma.

En PANAMA se permite a las cooperativas recibir de personas públicas o privadas, asignaciones, legados y otros aportes destinados a incrementar su patrimonio o a ser consumidos de conformidad con la voluntad del aportante. En ambos casos estarán orientados al cumplimiento del respectivo objeto social —artículo 84-.

La forma de integración del patrimonio cooperativo está ubicado en el capítulo $V$ en cuanto al régimen económico, a través del artículo 64, que establece: «El patrimonio de la cooperativa estará consti- 
tuido por las aportaciones de los asociados, la parte de los intereses y excedentes que la asamblea no haya resuelto capitalizar, así como por las reservas los subsidios, donaciones, legados y otros recursos análogos que reciba con destino el incremento patrimonial.»

En El Salvador en el capítulo del régimen económico, el artículo 37, indica que el patrimonio de las cooperativas estará constituido por las aportaciones de los asociados, la parte de los intereses y excedentes que la Asamblea resuelva capitalizar y los subsidios, donaciones, legados y otros recursos son análogos que reciban. Con lo cual está contemplada la propiedad cooperativa individual, sea los aportes de los socios, que hemos indicado es disponible con las limitaciones de ley.

Las diferentes partidas que contribuyen a formar el patrimonio de las cooperativas hondureñas, se encuentran disgregadas en el artículo 41, ubicado en la Sección cuarta. Recursos económicos, que reza:

Los recursos económicos de las cooperativas serán variables y podrán constituirse en la siguiente forma:

Con las aportaciones y los ahorros de los cooperativistas, así como con los excedentes capitalizados y las reservas acumuladas.

Con bienes muebles e inmuebles, trabajo, industria, capacidad profesional o fuerza productiva que aporten los cooperativistas.

Con donaciones, herencias, legados, préstamos; créditos, derechos y privilegios que reciban de personas físicas o jurídicas; y

ch) con el producto de las ventas de certificados de participación y/o bonos que la cooperativa emita. Los certificados y bonos antes mencionados devengar para el interés que fija la Junta Directiva y no serán negociables. ${ }^{7}$

7 En ciernes se encuentra un proyecto de ley para las cooperativas de ahorro y crédito, en donde también se tratan los temas de patrimonio y capital social, en forma específica para este tipo de cooperativas. Veamos el contenido de las disposiciones propuestas:

\section{CAPITULO ॥}

\section{Capital, reservas y excedentes}

Artículo 31. El monto del capital social de las Cooperativas de Ahorro y Crédito no podrá ser inferior a cinco millones de lempiras. La comisión deberá actualizar por lo menos cada dos años el monto, con base al índice de precios al consumidor. 
En COSTA RICA, en el capítulo VI, del patrimonio social, artículo 66, una vez que se indica su naturaleza de variable e ilimitado, también se incluyen los fondos y reserva de carácter permanente, inciso b); las cuotas de admisión y solidaridad, una vez deducidos los gastos de constitución y organización, inciso c).

Asimismo el patrimonio está protegido contra, embargos preventivos a la cooperativa, mientras ella cumpla con los estatutos y la ley, que algún socio quisiera presentarle —artículo $73-{ }^{8}$. La existencia de la normativa de cooperativas de ahorro y crédito sometidas al régimen de intermediación financiera, en Costa Rica, ha dado un cambio significativo al tema de financiamiento, dado que la ley especial ha previsto diferentes fuentes de financiamiento de tales cooperativas, con requisitos y controles diversos. Lo cual lo encontramos en los siguientes artículos:

\section{CAPITULO IV}

\section{Operaciones}

Artículo 14. Las organizaciones cooperativas de ahorro y crédito financiarán sus operaciones con los siguientes recursos financieros:

Artículo 32. El capital social estará constituido por las aportaciones y capital institucional. Las aportaciones están conformadas en certificados de aportación obligatoria y certificados de aportaciones voluntarias, los cuales serán nominativos, indivisibles y transferibles a quienes reúnan.

Artículo 38. Los activos extraordinarios que adquieran las cooperativas conforme a lo dispuesto en el artículo anterior deberán ser vendidos por las cooperativas en subasta pública dentro de un plazo no mayor de dos (2) años a contar de la fecha de su adquisición. En casos debidamente justificados, este plazo podrá ser prorrogado por la Comisión hasta por ciento ochenta (180) días. Si a la expiración de dicha prórroga la cooperativa no hubiese vendido los activos extraordinarios, estará obligada a constituir una reserva del $25 \%$ anual hasta cumplir con $100 \%$ de su valor en libros.

Las cooperativas podrán conservar los bienes a que se refiere este artículo siempre que se destinen para obras que constituyan un beneficio a la comunidad, para fines culturales, bienes para su propio uso o para el bienestar de su personal, previa autorización de la Comisión Nacional de Bancos y Seguros.

8 Existe una Ley de Regulación de la Actividad de Intermediación Financiera de las Organizaciones Cooperativas, la cual rige a partir del 24 de mayo de 1994.Tiene un capítulo III Capital Social que repite lo indicado en la Ley de asociaciones cooperativas mencionada. 

a) Con su capital social.
b) Con la recepción de ahorros a la vista de sus asociados.
c) Con la captación de recursos de sus asociados.
ch) Con la contratación de recursos nacionales e interna- cionales. En este último caso, se requerirá la apro- bación previa del Banco Central de Costa Rica.
d) Con la recepción de donaciones y legados.
e) Con los demás recursos que estén en función de la na- turaleza y de los objetivos de estas organizaciones.

Artículo 15. El consejo de administración de cada cooperativa establecerá las tasas de interés que se pagarán por concepto del ahorro a la vista y de los depósitos a plazo.

Artículo 16. Las organizaciones cooperativas de ahorro y crédito podrán realizar, exclusivamente con sus asociados, las siguientes operaciones activas en el país:

a) Conceder préstamos, créditos y avales directos.

b) Comprar, descontar y aceptar en garantía: pagarés, certificados y cédulas de prenda, letras de cambio, hipotecas y, en general, toda clase de títulos valores e instrumentos comerciales.

c) Efectuar inversiones, en títulos valores emitidos por instituciones financieras del Estado, empresas reguladas por las Leyes Nos. 1644 del 26 de septiembre de 1953, 5044 del 7 de septiembre de 1972 y la 7201 del 10 de octubre de 1990, o pertenecientes al sistema financiero cooperativo y reguladas por esta Ley.

Artículo 17. Los préstamos, créditos y avales se otorgarán para los propósitos y en las condiciones que establezcan los reglamentos de cada cooperativa. Cada consejo de administración establecerá las políticas, en cuanto a las garantías y demás condiciones de esas operaciones; asimismo le corresponde otorgarlas; pero podrá delegar esas potestades en una comisión de crédito, nombrada por él mismo, o en funcionarios de la propia cooperativa, de acuerdo con los montos establecidos en los reglamentos.

Artículo 18. El límite máximo, en cuanto a préstamos, créditos y avales, que se puede otorgar a un asociado, directa o indirectamente, será del cinco por ciento de la cartera total de créditos o del diez por ciento del capital social, la suma que sea mayor. Las fianzas que otorguen los asociados están comprendidas en las limitaciones de este artículo. Todo contrato de crédito emitido por la 
cooperativa deberá expresar una razón, por la cual la Superintendencia General $\left({ }^{*}\right)$ podrá inspeccionar y verificar los planes de inversión relativos a dichos créditos, así como la comprobación del uso final de los recursos correspondientes.

(* Así modificado el nombre del ente contravalor bancario por el artículo 176 de la Ley Orgánica del Banco Central de Costa Rica No. 7558 de 3 de noviembre de 1995).

Artículo 22. Las comisiones e intereses de operaciones de préstamos y descuentos, vencidas a más de ciento ochenta días, devengados pero no percibidos, se contabilizarán como ingresos cuando se perciban. En Nicaragua y Panamá no existe referencia expresa en cuanto al patrimonio y su constitución. En cuanto a la propiedad cooperativa individual, en general está formada por los aportes al capital, los intereses que éste genere y los excedentes producidos durante el ejercicio económico anual de cada cooperativa, y que generalmente son aplicados de acuerdo con las operaciones realizadas por los socios y las socias con su empresa cooperativa.

La disponibilidad de los recursos económicos cooperativos, bajo el esquema de propiedad cooperativa individual, también forma parte de las disposiciones legales que cada país establece para indicar el monto, el acceso y los límites que tiene el socio o la socia cooperativistas cuando tengan interés en acceder a los mismos.

En El Salvador en el artículo 37, segundo párrafo, está permitido el acceso de los socios a los excedentes o ganancias con límite de la deducción de los gastos, de las reservas y una gran cantidad de contribuciones que cada legislación, en los diferentes países, establece. También es posible que sean objeto de impuestos.

\section{Límites de acceso de recursos financieros. El caso de las operaciones con terceros}

Las normas que impiden el acceso a los recursos por parte de los socios cuando los recursos provienen de actividades realizadas con terceros, son un lugar común, en casi todas las legislaciones cooperativas del mundo, de ahí que no sea excepción para el caso de la región centroamericana. 
En Honduras, bajo la calificación de excedentes netos generados por operaciones con no afiliados, se les destina, en forma preferente, a programas de desarrollo cooperativista-artículo 45 .

Mientras que en Costa Rica, las cooperativas deben contar con un permiso doble, de la asamblea de socios y del Instituto Nacional de Fomento Cooperativo, artículo 9. Y el destino de tales ingresos será dirigido a incrementar el fondo de educación de las cooperativas, según lo establece el artículo $84^{9}$.

En nuestra opinión, la indisponibilidad de tales ingresos parte de idea errónea, cuya base es que el socio no ha contribuido a generar esa riqueza, y por ello no debe gozar de sus beneficios.

Consideramos que si el socio no hubiera aportado su capital social y no se dieran las reservas integradoras del patrimonio social cooperativo, así como la actividad de los socios en su participación constante durante la vida total de la cooperativa, tal organización no existiría y no se darían los contratos que generan tales recursos.

No es cierto que el socio no colabore en su producción, únicamente lo que sucede es que proviene del apoyo económico, no proviene de los fondos existentes en el capital social, pero sí en el trabajo que se realizado en la cooperativa, lo cual ha dado como resultado que existan reservas que permiten obtener esos recursos para invertir en otro negocio.

Si los socios son dueños de la cooperativa y si ésta existe gracias a su participación económica y su gestión, no hay duda que parte de las ganancias deberían ser distribuidas entre éstos. Como parte de la propiedad individual limitada, también deberán existir normas que restrinjan el acceso a la totalidad de las ganancias; y eso por el patrimonio de una cooperativa que tiene muchos años de existencia no ha sido formado únicamente por los socios actuales. De tal modo que parte de esas ganancias sí deben ser parte de las reservas irrepartibles, pero también debe existir distribución equitativa de los fondos

9 Esta vía se mantiene en la Ley de cooperativas de ahorro y crédito que realizan intermediación financiera, Ley No. 7391, el artículo 24 reza: «Las operaciones señaladas en el artículo anterior podrán efectuarse con asociados o con no asociados. Los excedentes generados por las operaciones con estos últimos, no serán retornables y deberán destinarse a reservas irrepartibles.» 
ganados, que por un lado fortalezca el patrimonio cooperativo y por otro lado incentive a los socios a proponer nuevos proyectos que generen más recursos.

\section{Beneficios, exenciones: impuestos, tasas, Impuesto de la Renta a las Cooperativas de Centroamérica}

Como una forma de protección del patrimonio cooperativo encontramos diferentes disposiciones legales tendientes a evitar la disminución del mismo. Esto permite una mayor disponibilidad de recursos por parte de la cooperativa, en su vida cotidiana.

Los beneficios que excluyen a las cooperativas como sujetos del impuesto de la renta, se basan en considerar que no son organizaciones generadoras de lucro, como objetivo esencial, sino dedicadas al servicio de sus miembros y la sociedad en que se insertan. De ahí que fuera importante tomar en cuenta el aspecto de la naturaleza de las cooperativas en Centroamérica, como contribuyentes al desarrollo económico, cultural y democrático de cada país, en donde funcionan.

En el caso de Guatemala es interesante llamar la atención acerca de la existencia por imperativo legal, de utilizar los modelos de estatutos oficiales, denominados estatutos uniformes, redactados por el Instituto Nacional de Cooperativas, es por ello, que en cuanto al tema de financiamiento quedarán determinados desde este momento, los aspectos que obligatoriamente estarán presentes en esos instrumentos de constitución y funcionamiento de los entes cooperativas de ese país y que no son considerados reserva de ley, de tal modo que se cumple siempre y cuando sean tomados en cuenta los requisitos establecidos en el artículo 19 de la ley cooperativa de ese país.

Los artículos más importantes con sus respectivos incisos los transcribimos en seguida:

\section{Artículo 11. Estatutos uniformes}

El Instituto Nacional de Cooperativas formulará estatutos uniformes para cada uno de los tipos de cooperativa, los cuales podrán ser adoptados por las cooperativas que se constituyan o modifiquen para el caso. Cuando se adopten estatutos uniformes, en el acto correspondiente bastará hacer mención a tal circunstancia, sin que sea necesario incluir su texto. 


\section{Constitución e inscripción de Cooperativas}

\section{Artículo 19. Acto de constitución}

La Cooperativa podrá constituirse por escritura pública o bien por acta constitutiva de la misma autorizada por el alcalde de la jurisdicción, y contendrá además de los requisitos generales de dichos instrumentos, lo siguiente:

g) La forma y reglas de distribución de los resultados obtenidos durante el ejercicio social respectivo.

h) El porcentaje que se destine a la reserva irrepartible, el cual no puede ser inferior al cinco por ciento (5\%) de los excedentes.

i) La forma de transmitir las aportaciones entre los asociados.

En HONDURAS el artículo 56, inciso a) exonera a la renta, los bienes y operaciones de las cooperativas del pago de impuestos fiscales, salvo en lo relacionado y opera para todo tipo de cooperativas - cualquier grado- y entidades auxiliares —artículo 58-.

De la legislación hondureña entresacamos aquellas exoneraciones que más destacan en el artículo 56, el cual establece un régimen general de exoneración de impuestos por los bienes que tenga la cooperativa, cuando reciba donaciones, o bien, en los programas de vivienda cuando la cooperativa sea tradente. Asimismo, en cuanto a la exportación de bienes no tradicionales. Ahora bien, en el siguiente artículo se regula el control del goce de tales beneficios a través del Instituto hondureño de Cooperativas, el cual debe informar a la Secretaría de Hacienda y Crédito Público, con el fin de que revoque, suspenda o restrinja el beneficio, previa audiencia a la cooperativa afectada.

Costa Rica presenta el mismo panorama, pues a las cooperativas y demás entes de tal naturaleza no se les considera sujetos de impuesto de la renta - artículo 63- También es importante anotar que la Ley que eliminó todo tipo de exoneración redujo considerablemente el contenido del artículo sexto de la ley costarricense, a partir del año 1992, con base en la Ley n. 7293, que derogó los incisos a, b, d, e, f, y k del artículo 6.

En la mayoría de las legislaciones cooperativas centroamericanas, salvo en Guatemala, se promulgó un extenso articulado que incluyó gran cantidad de exoneraciones, como una forma de estímulo de las cooperativas. 
En los casos del El Salvador, Guatemala ${ }^{10}$ y Nicaragua ${ }^{11}$, también existe un límite al goce de esos beneficios, pues si la autoridad de aplicación correspondiente, comprueba que han sido usados indebidamente o desviados, podrá revocarlos, suspenderlos y establecer las correcciones correspondientes a las cooperativas que han incurrido en la conducta indebida.

A modo de ejemplo transcribimos la legislación nicaragüense y salvadoreña, tomando en cuenta que en Costa Rica el artículo sexto fue dejado sin efecto, en su mayor parte, por la ley de 1992, en la cual se eliminó todo tipo de exoneraciones.

\section{Al respecto el CAPITULO IV. De la protección estatal}

Artículo 23. Incentivos fiscales y ayudas especiales, lo regula cuando reza:

Las cooperativas gozan de la protección del Estado, que proporcionará la ayuda técnica y financiera necesarias y especialmente las siguientes:

a) Exención total del impuesto del papel sellado y timbres fiscales;

b) Exención del impuesto sobre compra-venta, permuta y adjudicación de inmuebles, herencias, legados y donaciones, cuando sean destinados a los fines de las cooperativas;

c) Exoneración de impuestos, derechos, tasas y sobrecargos en las importaciones de maquinaria, vehículos de trabajo, herramientas, instrumentos, insumos, equipo y material educativo, sementales y enseres de trabajo agrícola, ganadero, industrial o artesanal, siempre que no se manufacturen en el país o en el área centro-americana. Esta exoneración será aplicada en cada caso por el Ministerio de Economía, previo dictamen favorable del INACOP, comunicada al Ministerio de Finanzas para los efectos aduanales; $y$

d) Las oficinas, empresas y funcionarios del Estado, de las Municipales e instituciones autónomas o descentralizadas tramitarán con la mayor celeridad todo asunto o gestión pertinente a las cooperativas, prestándole apoyo y auxilios.

\section{Artículo 24. Sanciones por mal uso de las exoneraciones}

Los objetos a que se refiere el inciso c) del artículo anterior, sólo pueden ser adquiridos y utilizados por las cooperativas, federaciones y confederación para sus propios fines. En caso de contravención a lo dispuesto, los infractores serán obligados al pago de los impuestos y a las sanciones que determina el artículo 30 de la presente ley. Los bienes muebles adquiridos de acuerdo al inciso c) del artículo anterior, no podrán ser negociados antes de los cuatro años de ser adquiridos, salvo que por el desarrollo de la cooperativa se haga necesaria una negociación, podrá efectuarse previa calificación y autorización del organismo rector.

11 Para evitar un situación de desventaja frente al resto de empresas que funcionan en el mercado nicaragüense, la legislación manifiesta que las empresas cooperativas nunca gozarán de menores beneficios, de aquellos establecidos para el resto de empresas. Literalmente lo encontramos en el artículo 75: «En ningún caso, las cooperativas gozarán de un régimen de protección o privilegios menor del que gocen empresas, sociedades o asociaciones con fines u objetivos similares desde el punto de vista social o económico.» 
NICARAGUA:

Artículo 74. Con el objeto de estimular el movimiento cooperativista, se otorga a favor de las cooperativas, los siguientes privilegios y exenciones:

a) Exención de impuesto de timbre y papel sellado.

b) Exención de los demás impuestos fiscales.

c) Exención de impuesto o derecho de importación sobre maquinaria, herramientas, repuestos de las mismas y sobre todo equipo, materiales y enseres necesarios para su funcionamiento.

d) Publicación gratuita de todos los documentos, en el periódico oficial; $y$

e) Goce de todas las demás ventajas que otorguen a las cooperativas las leyes de la República.

NICARAGUA:

Artículo 76. En cuanto a los privilegios y exenciones a que se refiere el Art. 74, el Ministerio de Economía tendrá la facultad de revocarlos, suspenderlos o restringirlos en cualquier momento que el Departamento de Promoción del Cooperativismo compruebe que una cooperativa está haciendo uso indebido de las exenciones.

No hay duda que el modelo seguido en los países centroamericanos presenta muchas analogías, como lo veremos más adelante. En el tema de exoneraciones, en El Salvador, también se presenta una amplia lista de las mismas, a través del artículo 62, ubicado en el CAPITULO VIII, denominado DE LAS OBLIGACIONES Y DEL REGIMEN DE PROTECCION:

La norma reza:

Artículo 62. Los privilegios que se otorgarán, de acuerdo con esta ley, a las asociaciones cooperativas, son los siguientes:

a) Exención de impuestos de papel sellado, timbres y derechos de registro, para los documentos otorgados por las asociaciones cooperativas en favor de terceros o por éstos en favor de aquéllas, en los casos en que las asociaciones cooperativas deban pagarlos; así como en todas las actuaciones judiciales en que tengan que intervenir, como actor o como reo, ante los tribunales comunes;

b) Exención de todo impuesto de importación sobre maquinaria, herramientas, repuestos, fertilizantes, insecticidas, artículos de 
consumo y construcción y animales que utilicen las asociaciones cooperativas para contribuir al desarrollo directo de la agricultura, de la ganadería o de la industria, siempre que no se produzcan ni manufacturen en el país en calidad aceptable a juicio del Instituto Salvadoreño o Fomento Cooperativo, o que la producción nacional no abastezca suficiente el mercado.

Los bienes que importen las asociaciones cooperativas, acogiéndose a las reglas del párrafo anterior, los destinarán exclusivamente a su propio uso y consumo, sin que puedan comerciar con ellos;

c) Exención de impuestos fiscales y municipales sobre su establecimiento u operaciones;

d) Inserción gratuita en el Diario Oficial de las publicaciones que ordena la ley o su reglamento;

e) Franquicia postal;

f) Derecho de acarreo preferente para los artículos alimenticios de primera necesidad y rebaja del $10 \%$ de los fletes por los artículos que se transportan en las empresas del Estado y en las particulares que reciban subvención oficial.

Los privilegios concedidos en este artículo se otorgarán a petición de la asociación interesada, por Decreto Ejecutivo en el Ramo de Economía, y le serán concedidos total o parcialmente, previa justificación con audiencia del Ministro de Hacienda, por el plazo de uno a cinco años, a partir de la fecha de su otorgamiento.

Artículo 63. Si el Instituto Salvadoreño de Fomento Cooperativo comprobare que la cooperativa no está funcionando como tal, o que esté haciendo mal uso de los privilegios que constituyen el régimen de protección, podrá suspender, restringir o revocar dicho régimen, para la asociación de que se trate.

Artículo 64. En ningún caso las asociaciones cooperativas gozarán en el país; de un régimen de protección menor del que gozan empresas, sociedades o asociaciones con fines similares desde el punto de vista social y económico.

Artículo 65. El Poder Ejecutivo en el Banco respectivo reglamentará la concesión de los privilegios a que se refiere el artículo 62 en forma que pueda revocarlos, suspenderlos o restringirlos, en cualquier momento en que el Instituto Salvadoreño de Fomento Cooperativo, compruebe que una asociación cooperativa está haciendo uso indebido de ellos.

Mientras el Poder Ejecutivo no emita la reglamentación a que se refiere este artículo, el mismo queda facultado para resolver los casos específicos que se le presenten. 
La lista es amplia, lo que se debe estudiar es si realmente las autoridades gubernamentales han estado dispuestas a reconocer tales beneficios. ${ }^{12}$

\section{Características de las aportaciones sociales}

Las aportaciones sociales son personales, la ley las individualiza a través de ciertos requisitos, entre ellos que se emiten bajo la forma de títulos nominativos, y que su transferencia únicamente se puede hacer a través del acuerdo del Consejo de administración. Salvo en los países donde se ha legislado sobre los derechos sucesorios del socio, en que podrían pasar a manos de los herederos. Pertenecen a la propiedad cooperativa individual.

La legislación establece la forma en que se pagan los aportes por parte de los miembros de cada cooperativa; la valoración de las mismas cuando no son en dinero en efectivo, así como la preferencia de las cooperativas frente a otros acreedores.

En algunos países la valoración se remite a las normas mercantiles, por reenvío a la normativa comercial, como es el caso de Costa Rica. En otros, se encuentra contemplado dentro de la misma legislación, por ejemplo, en Panamá, el artículo 67 establece diferentes criterios de valoración de las aportaciones en bienes y servicios.

Encontramos aportaciones obligatorias al capital social, el origen proviene de la ley, con especificaciones a través de los estatutos o acuerdos de la Asamblea. También se pueden dar aportaciones voluntarias al capital social, la Asamblea General puede admitir aportaciones voluntarias de los socios. En el acuerdo social —estatuto- se puede especificar si estas aportaciones voluntarias se incorporan o no al capital social.

El modelo general sigue aplicándose en este tema, así en El Salvador, según el artículo 38:

Las aportaciones se sujetarán las siguientes normas:

a) Los aportes podrán ser hechos en dinero, bienes muebles, o inmuebles o derechos, de acuerdo con lo que dispongan los

12 En Panamá lo encontramos en los artículos 106 a 110, donde las exoneraciones están expuestas en forma amplia. 
estatutos de la asociación cooperativa, según la naturaleza de ésta.

b) La valoración de los aportes en bienes o derechos se efectuará de acuerdo con el procedimiento que señala el reglamento de la presente ley; no podrá ser valorizado como aporte el trabajo personal de los promotores de la asociación cooperativa; los valores no podrán ser hechos, en ningún caso, por el simple acuerdo de los miembros de la asociación, ni de sus organismos directos;

Sin perjuicio de lo dispuesto en el artículo 45 de esta ley, los aportes serán representados mediante «certificados de aportación» que deberán ser nominativos, indivisibles, de igual valor. Los certificados sólo podrán ser transferibles, previa autorización del Consejo de Administración. Los certificados de aportación no son negociables;

Cada certificado de aportación podrá representar una o más aportaciones, en las condiciones que determinen los estatutos.

Artículo 39. Las aportaciones totalmente pagadas y no retiradas antes del cierre del ejercicio podrán devengar un interés nunca mayor del $6 \%$ anual, pagadero con cargo a los excedentes obtenidos por la cooperativa, si así lo dispone la Asamblea General. Los intereses se calcularán a partir del último día del mes en que cada aportación fuere pagada.

Artículo 40. Cada asociado de una cooperativa deberá aportar por lo menos el valor de un certificado de aportación.

En forma similar, las aportaciones están sujetas a las condiciones antes mencionadas, según artículo 65 de Ley de cooperativas de Panamá; en Nicaragua, en el capítulo VII, del régimen económico y las provisiones sociales, en los artículos del 48 al 50; Costa Rica, artículos 67 y 68; en El Salvador en el artículo 38. En el primero es más amplio el origen de los bienes entregados como aporte, pues se toma en cuenta el trabajo productivo e industrial, con un espectro más amplio de lo que pueden ser los bienes que se incorporan al patrimonio cooperativo, en forma de capital social.

En concreto la norma costarricense establece en el numeral 67:

«El capital social estará compuesto por las aportaciones ordinarias en dinero efectivo, en bienes muebles e inmuebles, en derechos, en trabajo, industria, capacidad profesional o fuerza productiva que hagan los asociados y sus familiares, y estarán representados en certificados de aportación de igual valor nominal. 
Las aportaciones que no sean en dinero efectivo, se valuarán al tiempo de ingresar la persona a la cooperativa, de conformidad con lo que al respecto establecen los estatutos.»

La importancia del aporte en trabajo, industria, capacidad profesional o fuerza productiva que hagan los asociados y sus familiares, encuentra mayor peso en el modelo cooperativo de autogestión, donde el aporte esencial al capital social de las cooperativas que se introducen en este modelo, es el trabajo humano. ${ }^{13}$

\section{Tope máximo}

En Nicaragua y Costa Rica existe un tope máximo de participaciones de cada socio, su monto es el $10 \%$ del capital social, artículos 51 y 41 respectivamente. El efecto ante la superación de ese límite podría ser la posible disminución del capital social de la cooperativa, que podría llevar su disolución, porque un mayor aporte no podría influir en las cooperativas de base, según el principio cooperativo de participación cooperativa, que indica que un socio un voto.

Pero sí tomaría otro rumbo, en el caso de las organizaciones cooperativas de segundo grado, donde el poder político puede ser controlado por el poder económico de los entes cooperativos participantes, y como uno de los criterios de mayor peso, cuando se debe tomar la decisión en cuanto a la distribución de votos para los miembros de cada ente de segundo o ulterior grado. Aunque sabemos que también se pueden tomar en cuenta otros criterios para realizar tal distribución, como son el volumen de operaciones y el número de socios de cada cooperativa participante.

\section{Capitalización de excedentes e intereses}

Es posible para las cooperativas obtener un financiamiento interno, a bajo costo, por medio de la capitalización de los excedentes. Generalmente, cuando se hace la asamblea general ordinaria, el

13 En Costa Rica, a partir de la reforma de 1982, se introdujeron dos modelos cooperativos más. El modelo autogestionario corresponde a las cooperativas de trabajo asociado. También se introdujo la forma cogestionaria, a partir de la propiedad compartida dentro del patrimonio cooperativo, entre empresarios y trabajadores, donde el empresario puede ser el Estado, a este último modelo se le llama cogestionario. 
Consejo de administración lleva una propuesta para aplicar los excedentes. Una de las proposiciones puede ser la no distribución pero sí capitalización temporal de los excedentes.

En HONDURAS, el artículo 44 inciso b) prevé la formación de fondos especiales con los excedentes. El Salvador, según artículo 49, permite a las cooperativas, vía asamblea general, capitalizar los intereses y excedentes correspondientes a los asociados, en vez de distribuirlos.

También las cooperativas pueden obtener recursos provenientes de los fondos de reservas, como es el caso de Honduras, en donde se permite usar sus fondos de reserva u otras disponibilidades, excepto la reserva legal, en inversiones que proporcionen beneficios para las mismas, siempre que no se afecten el patrimonio y excedentes de sus asociados.

La clase de inversión estará sujeta al Reglamento o Estatutos, donde se considerará la clase de inversiones a efectuar por el Consejo de Administración. Pero tales títulos tienen beneficios como es el interés pero límites en la libertad de disposición, por parte del titular, dado que no son negociables ${ }^{14}$.

\section{Aportaciones de los socios que no entran a formar parte del capital social. Fondos internos de las Cooperativas}

Los socios pueden entregar a su cooperativa fondos diferentes a los que integran el capital social. Fondos de pensiones, depósitos a plazo, reinversión de sus excedentes.

En los últimos años, se han ampliado las posibilidades de las cooperativas de intervenir en el mercado financiero y crear nuevos productos, entre éstos es muy usual los fondos mutuales voluntarios, dirigidos a fortalecer una futura pensión; a crear seguridad a los futuros deudos ante la exigencia de atender pompas fúnebres, o

14 Esto lo encontramos en la SECCION CUARTA. RECURSOS ECONOMICOS de la ley hondureña, artículo 41 inciso ch), expresa: «Con el producto de las ventas de certificados de participación y/o bonos que la cooperativa emita. Los certificados y bonos antes mencionados devengan para el interés que fija la Junta Directiva y no serán negociables.» 
bien, en el actual momento, creando fondos que sufraguen la entrada a lecciones - ahorro escolar-; canasta básica en Semana Santa o Navidad; clubes de recreación, entre otros. O bien, el interés de los socios de depositar sus ahorros o el fruto de largos y duros años de trabajo, que se plasman en las denominadas prestaciones laborales. El caso panameño es amplio, dada la novedad de la legislación, incorpora múltiples posibilidades, actuales, de ese tipo de inversión voluntaria que se ofrece como producto al socio.

Un ejemplo lo podemos sustraer de la ley panameña:

Artículo 77. Las cooperativas podrán constituir y manejar, de acuerdo con las leyes vigentes, fondos de retiros, cesantías y pensiones y jubilaciones especiales, directamente o por medio de sus federaciones y entidades auxiliares, estos fondos serán inembargables.

Artículo 78. La cooperativa podrá crear un fondo rotatorio con los excedentes e intereses de los asociados, que serán devueltos en caso de que éstos se retiren. La junta de directores, deberá reglamentar el aporte mínimo y máximo, que debe ahorrar cada asociado, el período de rotación del fondo y el porcentaje de los intereses y excedentes que se capitalizarán, este fondo se sujetará a las reglas siguientes:

1. El fondo creado con los intereses y excedentes podrá ser incrementado con otros aportes, tales como efectivo descuentos autorizados por el asociado o partidas de los fondos de la cooperativa. En todo caso, el fondo rotatorio debe tener por objetivo el fomento de actividades productivas de la cooperativa.

2. La asamblea podrá acordar el reconocimiento de un interés por el uso del capital aportado a este fondo.

La negrita la hemos aplicado para resaltar la variedad de figuras de fondos, así como la particularidad del fondo rotatorio, el cual tiene un destino coincidente con el concepto de la cooperativa como empresa y el interés de ofrecer instrumentos financieros a los socios(as) para que realicen sus actividades profesionales o artesanales.

Las posibilidades son muy variadas como hemos visto. En algunos casos, se permite el financiamiento de las cooperativas por medio de la emisión de bonos, autorización que proviene de la misma ley coo- 
perativa. En otros casos, la ley remite a la normativa comercial como marco de desarrollo de tales acciones bursátiles.

Tan sólo en Guatemala se prohíbe expresamente a las cooperativas, según el artículo 29 denominado: PROHIBICIONES, que apunta:

Se prohíbe a las cooperativas:

e) Especular con títulos en operaciones de bolsa.

Finalmente, sin agotar posibilidades, la cooperativa interesada puede ser certificada para ingresar a una bolsa de valores. Además de establecer el registro forzoso de la emisión de bonos y obligaciones, como sucede en Honduras -artículo 10- que permite tener mayor seguridad en la inversión, dada la seguridad jurídica que ofrece el registro de tales operaciones.

En PANAMA, dentro de un marco amplio, ofrecido por el mismo desarrollo del país, donde abundan los bancos internacionales, está bien definido el objetivo de la emisión de certificados de inversión u otros valores redimibles y de plazo fijo que emitan las cooperativas. Los requisitos de forma para su emisión y circulación en el mercado, pues el artículo 123 establece que si son títulos valores deben cumplir con lo establecido en el Código de Comercio.

A continuación transcribimos las normas correspondientes a la emisión de esos títulos.

Artículo 80. Las cooperativas podrán emitir certificados de inversión y otros títulos-valores redimibles y de plazo fijo, emitidos para reforzar el activo de las cooperativas. Su producto se destinará al cumplimiento de objetivos específicos.

La emisión de estos certificados de inversión y otros títulos valores debe ser aprobada por asamblea y autorizada previamente por el IPACOOP.

Artículo 81. Los certificados de inversión y otros títulos valores serán nominativos y transferibles, y su valor nominal, así como el interés que devenguen, se abonará con preferencia a cualquier otro pago que tenga que realizar la cooperativa.

Artículo 82. Los intereses y demás beneficios que provengan del capital invertido por los asociados, sus depósitos y los títulos valores invertidos por los asociados y terceros estarán exentos de toda 
clase de impuestos, derechos, contribuciones o gravámenes de carácter general.

Artículo 83. Las cooperativas podrán asumir todas las formas de pasivos y emitir obligaciones que suscribirán los asociados a los terceros conforme a las condiciones que establezca la respectiva reglamentación. ${ }^{15}$

\section{La distribución de excedentes como origen de las reservas cooperativas}

Es norma universal, en la legislación cooperativa, la formación de reservas a partir de la generación de ganancias o excedentes. Básicamente son tres reservas: legal, patrimonial o institucional; de educación y de bienestar. Además de esas reservas, es posible establecer otras cuyos fondos tienen diferentes destinos, que concuerdan con la actividad económico social que desarrolla la cooperativa. La definición de las reservas permite el nacimiento de los excedentes.

En Costa Rica, en el año 2001, los diputados representantes del Movimiento Libertario, liberales a ultranza, pretendieron imponer el impuesto de renta y eliminar las reservas, desconociendo su función. Hasta el momento no se ha vuelto a presentar la discusión legislativa, sin embargo, el peligro de su eliminación es latente.

Los excedentes surgen una vez que en el balance anual se descuenten los gastos generales del período. Además de las provisiones de ley, generalmente destinadas a sostener a entes cooperativos, sea de representación, integración y defensa o bien con fines educativos. En Costa Rica, las cooperativas de ahorro y crédito, por una ley especial fueron obligadas a contribuir a un fondo particular de agricultores, en el año 2001 y se mantiene vigente.

A partir de un límite inferior, los porcentajes varían de una cooperativa a otra.

En forma general, el esquema es el mismo, tomamos el ejemplo de PANAMA, como muestra de la redacción y provisiones que debe

15 En Costa Rica, los artículos 77 y 78 permitían emitir obligaciones, pero fue derogado en los años 90, sin embargo, algunas cooperativas invierten en la Bolsa de valores, bajo la ley especial que la rige. 
hacer cada cooperativa, en forma concreta, a través de un acuerdo de asamblea, o sea con la participación de los miembros y titulares de la cooperativa.

Artículo 70. Los excedentes que arroje el balance anual, después de descontados los gastos generales y las provisiones, serán distribuidos por acuerdo de la asamblea, en la siguiente forma y orden de prelación:

1. Por lo menos, el diez por ciento (10\%) para la reserva patrimonial; nueve y medio por ciento $(9,5 \%)$ para el fondo de previsión social; diez por ciento (10\%) para el fondo de educación; medio por ciento $(0,5 \%)$ para el fondo de integración y cinco por ciento (5\%) para constituir, en IPACOOP, el fondo anual especial para el fomento y desarrollo cooperativo.

2. La suma que señala el estatuto o la asamblea para fines específicos,

3. El interés que devenguen las aportaciones, conforme lo establezca el estatuto.

4. La devolución a los asociados, en proporción a las operaciones que hubieran efectuado con la cooperativa o a su participación en el trabajo común.

En HONDURAS, el artículo 44 aclara que la reserva legal es acumulativa, dado que es irrepartible y la forma en que se mantendrá su valor, en el tiempo, Inciso a): $10 \%$ para reserva anual, acumulada anualmente, no repartible ... el fondo de reserva legal se invertirá en bonos $u$ otros títulos de fácil convertibilidad, emitidos por federaciones de cooperativas, instituciones bancarias o del Estado.

En todas las legislaciones cooperativas, las reservas son recursos financieros propios de la empresa cooperativa, su origen está en los excedentes del resultado económico anual.

La ley las establece en forma obligatoria, pero también las hay estatutarias y por acuerdo de asamblea.

\section{La reserva legal o patrimonial}

La reserva patrimonial o legal tiene como función ayudar al desarrollo de las cooperativas y ofrece un colchón en caso de pérdidas, vemos una norma clara en Nicaragua: 
Artículo 55. Si el balance arrojase pérdida, ésta será absorbida por el fondo de reserva, si éste fuera igual o superior a aquélla. Si fuere inferior, el saldo será diferido y cubierto con los excedentes de períodos subsiguientes.

Eso sí, podría llegar el momento de crecimiento desmedido de la reserva patrimonial, esto cuando la cooperativa tiene una administración sana y no es necesario utilizarla. Por tal razón, en algunos casos, la ley cooperativa establece un tope en el crecimiento de la reserva legal.

En Panamá encontramos un ejemplo claro de las limitaciones legales al crecimiento de la reserva patrimonial, una vez que la ley define claramente su objetivo en el primer párrafo del artículo 72, que transcribimos a continuación.

Artículo 72. La reserva patrimonial tiene por objeto asegurar a las cooperativas la normal realización de sus actividades, habilitarlas para cubrir las pérdidas que se produzcan en un ejercicio económico y ponerlas en situación de satisfacer exigencias imprevistas o necesidades financieras que puedan presentarse. y se regirá por las disposiciones siguientes:

1. Será facultad de la asamblea establecer que la reserva patrimonial sea limitada y tal determinación deberá establecerse en el estatuto de la cooperativa.

2. Cuando la reserva patrimonial sea limitada, no podrá exceder del veinte por ciento (20\%) de las aportaciones pagadas.

3. Para constituir e incrementar la reserva patrimonial se destinará, por lo menos, el diez por ciento (10\%) de los excedentes netos obtenidos. Ingresarán, además, los fondos irrepartibles y todas las sumas que no tuvieren destino específico, sin perjuicio de que pueda incrementarse por otros medios.

4. Si la reserva patrimonial disminuyese por cualquier causa, el IPACOOP deberá ser notificado inmediatamente. Los excedentes futuros serán utilizados para restituir el nivel que tenía anteriormente.

NICARAGUA, en el artículo 52 de su ley cooperativa, estipula que las reservas se integrarán de acuerdo con la naturaleza de cada cooperativa, siguiendo el marco general de Panamá.

En Costa Rica, el destino de la reserva legal está establecido en el artículo 70, norma que contempla tanto las pérdidas como el acceso 
al recurso de los fondos del capital social, si no alcanzare la reserva legal a cubrir las pérdidas. ${ }^{16}$

Una fuente de discriminación ha sido el caso de las cooperativas de autogestión, en Costa Rica. Nacidas básicamente para la atención de los grupos de campesinos, pero con un contenido más amplio, como lo podemos ver en la definición del artículo 99, estas cooperativas fueron sometidas a un régimen más pesado y gravoso, en el caso de las reservas y provisiones. Situación que no ha cambiado pese a los constantes intentos de obtener una nueva ley cooperativa, que se han venido realizando en Costa Rica, en los últimos 15 años.

El artículo 99 da la definición de las cooperativas de autogestión, por medio de la precisión de su contenido. Una justificación del tratamiento diferente en cuanto a reservas, entre otras situaciones, podría encontrarse en algunos incentivos que al principio se regularon ${ }^{17}$, pero que ahora no funcionan. Podemos citar la relación estrecha de los miembros de esas cooperativas con el Instituto de Desarrollo Agrario, para obtener tierras de trabajo.

En estas cooperativas el capital social es aportado por el trabajo personal de los miembros, quienes no pueden tener bienes de producción a su nombre y participan de lo que la ley de asociaciones cooperativas ha definido como propiedad social con carácter indivisible, lo cual no ofrece ninguna contribución al concepto de propiedad cooperativa colectiva, dado que la disposición individual de la misma es imposible jurídicamente.

El artículo 99 reza: «Las cooperativas de autogestión son aquellas empresas organizadas para la producción de bienes y servicios, en las cuales los trabajadores que las integran dirigen todas las actividades de las mismas y aportan directamente su fuerza de trabajo, con el fin primordial de realizar actividades productivas y recibir, en proporción a su aporte de trabajo, beneficios de tipo económico y social. Las unidades

16 Artículo 70. Si el patrimonio social de la cooperativa disminuyera por pérdida en el ejercicio de las operaciones sociales, podrá ser repuesto con fondo pertenecientes a la reserva legal, según lo dispongan los estatutos o lo acuerde la asamblea. Si la reserva legal no alcanzare para cubrir las pérdidas, éstas se cargarán en forma proporcional al capital social pagado o suscrito según lo dispongan los estatutos en cada caso.

17 El artículo que se transcribe es una muestra de la buena voluntad existente al momento de promulgarse esta reforma a la Ley de asociaciones cooperativas, en 1982: Artículo 115. El Gobierno Central, organismos públicos descentralizados, el Sistema Bancario Nacional e instituciones financieras en que tenga participación el Estado, apoyarán con prioridad la constitución y desarrollo de cooperativas de autogestión. 
de producción destinadas al funcionamiento de éstas, estarán bajo el régimen de propiedad social con carácter indivisible.»

La gran cantidad de reservas y cargas especiales de este modelo de cooperativas, se encuentra marcado en el siguiente artículo, por medio de la letra negrita:

Artículo 114. Los excedentes netos deberán destinarse:

a) Obligatoriamente:

1) El10\% a constituir la reserva legal.

2) Por lo menos el $6 \%$ para el fondo de bienestar social.

3) Un mínimo de $15 \%$ a realizar inversiones productivas que amplíen la capacidad económica de la empresa, siempre y cuando las inversiones cumplan con lo que establezca el reglamento de inversiones que elaborará la Comisión Permanente de Cooperativas de Autogestión. En caso de que no se realice la inversión, éstos pasarán a reforzar el fondo nacional de cooperativas de autogestión para ser destinado a inversiones en empresas cooperativas de autogestión. La empresa recibirá la tasa de interés que la Comisión Permanente de Cooperativas de Autogestión previa consulta con el Instituto Nacional de Fomento Cooperativo, fije para estos efectos. El porcentaje destinado a las inversiones productivas será representado por certificados de aportación distribuidos entre los socios en proporción a sus aportes en trabajo.

4) El $4 \%$ a la formación de un fondo para la promoción y capacitación de empresas cooperativas de autogestión, que será manejado por la comisión Permanente de Cooperativas deAutogestión.

5) El $\mathbf{5} \%$ se destinará al fortalecimiento del fondo nacional de cooperativas de autogestión.

6) El $\mathbf{5 \%}$ para el financiamiento de las uniones, federaciones y confederaciones.

7) El $1 \%$ para el Consejo Nacional de Cooperativas.

b) Por decisión de la asamblea:

8) Distribuir el saldo entre los socios en proporción a su aporte del trabajo, para lo cual la empresa llevará un control de las horas trabajadas por sus socios, sirviendo dicho control de base para la distribución de los excedentes entre los mismos, según los estatutos de la empresa.

9) Cualquier otro fin establecido en los estatutos o que determine la asamblea. 
En algún momento es posible que los titulares de la cooperativa accedan a recursos generados por la cooperativa y que eran indisponibles. Esto sucede cuando la reserva legal equivalga a un tercio del capital suscrito actual, y entonces el artículo 69 de ley costarricense permite convertirlo en certificados de aportación, salvo en el caso de cooperativas de autogestión, en el tanto que el aporte es personal'18.

Producto de los regímenes diferentes de los modelos autogestionario y cogestionario, se prevé en la ley una ayuda estatal para tales cooperativas, sea mediante el otorgamiento de avales para obtener financiamiento, o bien, con la utilización de reservas dedicadas al Estado. Los siguientes tres artículos dan el texto claro de la vocación estatal:

Según artículo 116: La institución promotora o el Estado, quedan facultados para dar el aval correspondiente, a las cooperativas de autogestión, cuando sea necesario para la obtención de financiamiento. En el artículo 117, se establece la posibilidad para las cooperativas de autogestión y cogestión de contratar preferentemente con el Estado. Las oportunidades de inversión que surjan como consecuencia de la existencia de actividades económicas reservadas al Estado, podrán desarrollarse, preferentemente por cooperativas de autogestión o de cogestión entre el Estado y los trabajadores. También se previó la existencia de un fondo de preinversión, según artículo 118: La Oficina de Planificación Nacional y Política económica, a través del fondo de preinversión u otros fondos, destinados a propósitos similares, dispondrá recursos para el financiamiento, en condiciones preferenciales, de los estudios necesarios para constitución de cooperativas de autogestión.

Artículo 119. Y finalmente, podemos ver el reconocimiento de integrar las cooperativas con el resto del Estado, con el fin de conformar un subsistema del sector: "Corresponde a la Oficina de Planificación

18 COSTA RICA. Artículo 81. El fondo de reserva legal, al que se debe destinar por lo menos el $10 \%$ de los excedentes, tiene por objeto cubrir pérdidas imprevistas, debe ser permanente y no se podrá distribuir entre los asociados, ni en caso de disolución de la cooperativa. Cuando el fondo de la reserva legal equivalga a un tercio del capital suscrito actual, los incrementos posteriores, serán representados en nuevos certificados de aportación que sí se distribuirán entre los asociados, excepto en las cooperativas de autogestión. Este fondo de reserva legal podrá ser dedicado a diversas inversiones en bienes y derechos muebles e inmuebles, que por su naturaleza sean seguros, prefiriendo en primer término, operaciones financieras con los organismos superiores de integración cooperativa. 
Nacional y Política Económica, la planificación y la coordinación interinstitucional de los esfuerzos, apoyo y asesoría de las instituciones del Estado a las cooperativas, por medio de la creación de un subsistema para dicho sector. ${ }^{19}$

\section{Las otras reservas obligatorias: reserva de educación y bienestar social}

La reserva legal, patrimonial o institucional también existe en las empresas mercantiles no cooperativas. Pero las reservas de educación y bienestar social son propias de la organización cooperativa, responden al valor de solidaridad y al Principio de educación cooperativa.

La reserva de educación es diferente de la reserva de bienestar social, en COSTA RICA, el comportamiento de la segunda tiene sus peculiaridades, y esto porque este país cuenta con un seguro social universal, de tal modo que la mayoría de la población, nacionales y extranjeros pueden acceder a al servicio de salud. Por otra parte, por razón de la definición antes transcrita de las cooperativas de autogestión, donde el socio es propietario trabajador, tal modelo de cooperativas está excluido del servicio de salud, de tal modo que es en este caso único, en el cual realmente el fondo de bienestar social puede ser utilizado para suplir las necesidades de salud de sus miembros.

El ejemplo costarricense nos sirve de fundamento para conocer el prototipo de regulación del tema de reservas de educación y de bienestar social. Veámoslos:

Artículo 82. La reserva de educación se destinará a sufragar, dentro de la zona de influencia de las cooperativas, campañas de divulgación de la doctrina y los métodos cooperativos, cursos de formación y capacitación cooperativa, o a impartir educación general, de acuerdo con el reglamento respectivo elaborado por el INFOCOOP. La reserva de educación será ilimitada y para formarla se destinará por lo

19 En relación con las cooperativas de cogestión, la normativa costarricense establece: «Las cooperativas de cogestión además de los privilegios que confiere esta ley en el artículo 6 a las demás cooperativas, disfrutarán de exención de impuesto de consumo y ventas en proporción al porcentaje de asociados trabajadores que tenga la cooperativa y al porcentaje de los excedentes que entregue a los trabajadores, según una tabla que al respecto establecerá el reglamento mencionado en el artículo anterior.» 
menos el 5\% de los excedentes obtenidos. A ellas ingresarán además los excedentes de no asociados y beneficios indirectos, así como aquellas sumas que no tuvieren destino específico, sin perjuicio de que ésta pueda incrementarse por otros medios. Los intereses y las sumas repartibles que no fueren cobrados dentro del término de un año a partir de la fecha en que fue aprobada su distribución, caducarán a favor de la reserva de educación y reserva de bienestar social.

Subrayamos el anterior párrafo por la importancia que tiene la integración al fondo de educación y lo cual lo fortalece, por medio de la disposición legal de destinar obligatoriamente todos las ganancias de no asociados, beneficios indirectos, además de los intereses y sumas repartibles no reclamados dentro del plazo de caducidad de un año, contado a partir del momento de la aprobación del excedente.

En cuanto a la reserva de bienestar, la ley ofrece la posibilidad de establecer convenios con el ente competente para ejecutar la política de seguridad social en el país. Tales convenios son de gran importancia para los miembros de las cooperativas autogestionarias, por las razones antes mencionadas. ${ }^{20}$

Artículo 83. La reserva de bienestar se destinará a sus asociados, a los trabajadores de la asociación y a los familiares inmediatos de unos y otros, para ofrecerles ayuda económica y programas en el campo de la asistencia social, especialmente para aquellos servicios que no otorgue la caja Costarricense de Seguro Social, o no estén contenidos en las disposiciones sobre riesgos profesionales. Esta reserva también será ilimitada; a su formación se destinará por lo menos un $6 \%$ de los excedentes anuales de las cooperativas, y para su uso, destino o inversión deberá contarse siempre con la aprobación de la asamblea.

20 En relación con estos convenios, las cooperativas de autogestión, especialmente COOPESA. RL. Una cooperativa de servicios de aviación, han tenido que recurrir ante los tribunales, esto con el fin de obtener su reconocimiento como forma especial de organización, donde los trabajadores son a la vez patronos. Frente a la Caja costarricense de seguro social y el Banco Popular y de Desarrollo Comunal, en la década de los noventa, esa cooperativa estableció un recurso de amparo,dirigido a obtener el reconocimiento de su naturaleza cooperativa en el modelo de autogestión, el cual determina que patrono y trabajado coinciden en la misma persona. La consecuencia en relación con esas dos instituciones fue que la declaratoria judicial que impide el cobro como patrono, de la seguridad social por parte de la Caja costarricense y de la cuota patronal que existe como contribución obligatoria en el Banco popular. 
Artículo 84. La asamblea podrá acordar, por mayoría simple la aprobación de convenios por medio de los que extienda la seguridad social a los asociados y caso de ser necesario, en igual forma el aumento del porcentaje destinado al fondo de bienestar social.

Artículo 43. Los fondos señalados en el inciso a) del artículo anterior, tendrán los siguientes fines:

a) la reserva legal, para cubrir pérdidas que pudieran producirse en un ejercicio económico y responder de obligaciones para con terceros;

b) el fondo de educación para el fomento de la educación cooperativista en la forma en que lo establezcan el reglamento de esta ley y los estatutos de la asociación cooperativa. En igual forma encontramos previstas las reservas en El Salvador, a través del artículo 42 y 43; recordemos que Guatemala deja la toma de decisiones a las entidades cooperativas; en Honduras en el artículo 44, en Panamá según lo dispone el artículo 70 y Nicaragua según la norma número 52.

\section{Irrepartibilidad de las reservas}

Aranzadi ${ }^{21}$ hace la distinción entre reservas colectivas y reservas individualizadas. El autor indica que su destino es la financiación de la inmovilización de la estructura. Dice: «Parece que ante el objetivo de crecimiento y expansión que deben perseguir las cooperativas difícilmente estas reservas pueden ser excesivas.»

En relación con las reservas individualizadas corresponden a aquellas bonificaciones diferidas, o excedentes no distribuidos, son conocidos como capital rotatorio o «revolving fund», consiste en la retención de excedentes anuales, por parte de la cooperativa, que le permite financiarse ya sea por el año correspondiente o un mayor número de años, según lo dispongan los estatutos una forma de autofinanciación.

La norma general en todos los países es la misma, ni las donaciones, legados y los fondos provenientes de las reservas creadas por ley o por asamblea pueden ser distribuidos individualmente, y a favor de los socios, como si fueran utilidades.

21 Op. cit. p. 369. 
La normativa panameña resume el contenido general de la norma relacionada con la irrepartibilidad del patrimonio cooperativo, entre sus elementos, de las reservas.

En el artículo 79 encontramos lo siguiente: Las reservas patrimoniales, el fondo de educación, el fondo de previsión social. Así como las donaciones y legados son irrepartibles.

En NICARAGUA, el artículo 54 prevé esa irrepartibilidad; en El Salvador la norma se encuentra en el artículo 44; en Honduras en el artículo 44 y Costa Rica, en el artículo 82.

\section{Revaloracion de activos}

Otro tema de interés en cuanto al financiamiento de cooperativas es la posibilidad para éstas de otorgar el real valor a sus activos, como una forma de mostrar la realidad y tener una imagen en el mercado más sólida. Esta práctica contable-financiera encuentra ciertos límites, en las diferentes legislaciones cooperativas del istmo centroamericano. Uno de esos límites es la necesaria autorización de la autoridad de aplicación. En este caso expondremos cada una de las normas que contempla esa posibilidad, en relación con cada país:

NICARAGUA:

Artículo 60. La cooperativa podrá revalorizar sus activos previa autorización del Departamento de Promoción del Cooperativismo. En caso de incremento la totalidad de las sumas resultantes de la revalorización se acreditarán necesariamente al fondo de reserva. En caso contrario, se aplicará lo dispuesto al Art. 53.

\section{GUATEMALA:}

No existe nada al respecto.

HONDURAS:

Artículo 120. La cooperativa puede aumentar o reducir su haber social, el aumento por revalorización del patrimonio es lícito, pero su importe constituirá una reserva de la que no podrá disponer la cooperativa sino cuando se enajenen los bienes revalorados y se perciba en efectivo el importe de la plusvalía. 
EL SALVADOR:

Artículo 50. La asociación cooperativa podrá revalorizar sus activos previa autorización del Instituto Salvadoreño de Fomento Cooperativo. La totalidad de las sumas resultantes de la revalorización quedará en una reserva especial, hasta que la asociación haya realizado el valor de la revalorización; a medida que lo vaya realizando, este valor incrementará necesariamente su reserva legal sin que ésta pueda exceder el máximo establecido en el Art. 42; en caso de que excediere, pasará la diferencia al fondo de educación.

\section{COSTA RICA:}

Se denomina corrección monetaria:

Artículo 80. Los excedentes deberán destinarse, por su orden, a construir la reserva legal, la reserva de educación, la reserva de bienestar social, y cualesquiera otras reservas de bienestar social, y cualesquiera otras reservas establecidas por los estatutos; a cubrir las obligaciones provenientes de las cuotas de inversión; a pagar al CONACOOP el $2 \%$ de los excedentes, conforme con lo estipulado en el artículo 136 de esta ley; a pagar a CENECOOP hasta el 2,5\% de los excedentes líquidos al cierre de cada ejercicio económico, porcentaje éste que, a criterio del Consejo de Administración de cada cooperativa, podrá producirse de la reserva de educación. Los porcentajes correspondientes a la formación de reservas especiales deberán establecerse en los estatutos de cada cooperativa, con excepción de las reservas legales, de bienestar social y de educación, cuyos porcentajes mínimos se establecen en los artículos 81, 82 y 83 de esta ley. En el caso de las cooperativas de autogestión, el destino de los excedentes se regirá por lo estipulado en el capítulo XI de la ley N. ${ }^{\circ} 6756$ citada. Se faculta a las cooperativas para que, previa deducción de las reservas establecidas en el artículo 80 de la ley N. ${ }^{\circ} 6756$ y en los estatutos de cada asociación cooperati$\mathrm{va}$, mediante acuerdo de por lo menos dos terceras partes de su Consejo de Administración, puedan aplicar una corrección monetaria en procura de restituir el poder adquisitivo de las aportaciones de capital social de sus asociados. El INFOCOOP, previo criterio del CONACOOP, reglamentará el procedimiento y aplicación de lo aquí dispuesto. En todo caso, la asociación cooperativa que aplicare las técnicas de corrección monetaria y que, por efecto de ésta tuviera excedentes, deberán capitalizarlo en una cuenta especial por un mínimo de cinco años, y podrá a partir del sexto año, acreditar lo correspondiente al primer año, y así sucesivamente, al 
capital social ordinario. Lo anterior no regirá en los casos de muerte, invalidez o jubilación del asociado, en cuyo caso se girará al asociado, o en su defecto a sus beneficiarios, la totalidad de sus aportaciones y lo correspondiente por corrección monetaria, previa liquidación de las obligaciones pendientes con la asociación cooperativa.

\section{Otras fuentes de financiamiento interno de las Cooperativas en Centroamérica}

En relación con este aparte nos limitaremos a enunciar vía artículos y país, las otras posibilidades de financiamiento que hemos localizado en las leyes cooperativas de Centroamérica, que por su diversidad no nos permite una sistematización.

\section{Retencion de excedentes}

En Nicaragua y El Salvador, encuentra su fuente en el estatuto o acuerdo de Asamblea General, el objetivo es obtener un préstamo de los recursos que se han producido dentro de la cooperativa, y por un tiempo limitado.

NICARAGUA:

Artículo 61. El estatuto o la Asamblea General podrán autorizar que la cooperativa retenga a título de préstamo para operaciones específicas, en las condiciones que ellos señalen, pero respaldadas por Bonos de Inversión que serán regulados por el Reglamento, las siguientes sumas:

a) Una cantidad fija o proporcional deducida del valor bruto de las ventas o de los servicios que la cooperativa realice por cuenta de los cooperados; y

b) Una parte o la totalidad de los intereses y excedentes correspondiente a los cooperados.

Artículo 62. Los recursos o cualquier tipo de bienes de la cooperativa, así como la denominación social deberán ser usados sólo por los órganos autorizados de ella, y únicamente para cumplir sus fines. Los infractores de esta norma quedarán solidariamente obligados a indemnizar a la organización, sin perjuicio de las demás responsabilidades legales a que hubiere lugar. 
EL SALVADOR:

Artículo 51. Los estatutos o la Asamblea General podrán autorizar que la cooperativa retenga, a título de préstamo para operaciones y productivas específicas y con cargo de la devolución en las condiciones y plazos que ellos señalen, las siguientes sumas: a) Una cantidad fija o proporcional, deducida del valor bruto de las ventas o de los servicios que la asociación cooperativa realice por cuenta de sus asociados; b) Una parte no mayor de la mitad, de los intereses y excedentes correspondientes a los asociados. Estos préstamos serán respaldados por Certificados de inversión, que serán regulados por el Reglamento de esta ley.

Artículo 52. Los recursos y cualesquiera otros bienes de la asociación cooperativa, así como la firma social, deberán ser utilizados únicamente para cumplir sus fines. Los infractores de esta norma quedarán solidariamente obligados a indemnizarla de los daños y perjuicios a que hubiere lugar, además de la acción penal correspondiente.

\subsection{Apoyo estatal para recuperar dineros de asociados trabajadores en dependencias públicas}

La posibilidad de recuperar dineros debidos por los asociados a sus cooperativas y que están empleados por el Estado y otros entes públicos, se da en EL SALVADOR, donde existe una normativa especial para dar apoyo en gestiones de cobro.

Artículo 48. Los pagadores de las dependencias del Estado y de las Instituciones Oficiales Autónomas de los sueldos o salarios que sus empleados o trabajadores autoricen por escrito para aplicarse al pago de ahorro, aportaciones, préstamos, intereses o cualquiera otra obligación que como asociado de una cooperativa contraigan, hasta la completa cancelación de las mismas. Las sumas deducidas serán entregadas a las respectivas cooperativas de acuerdo con lo que disponga el reglamento de esta ley. Para que tenga aplicación lo dispuesto en este inciso es necesario que la asociación cooperativa de que se trate, solicite al Instituto Salvadoreño de Fomento Cooperativo (INSAFOCOOP) la autorización correspondiente. Caso éste resuelva favorablemente lo comunicará al Ministerio de Hacienda a fin de que este Ministerio resuelva lo pertinente autorizando o no a los pagadores respectivos, los descuentos solicitados. Los trabajadores del sector privado podrán autorizar las mismas deducciones de confor- 
midad con el procedimiento señalado en el artículo 136 del Código de Trabajo. En todo caso, las cantidades señaladas como cuota de retención, no excederán del $20 \%$ del sueldo o salario devengado por el empleado o trabajador, en el o los períodos de pago.

PANAMA también repite la norma de apoyo estatal a las cooperativas, siempre y cuando exista prueba escrita de la deuda, el siguiente artículo nos da el panorama panameño:

Artículo 115. Toda persona, empresa o entidad oficial o privada, estará obligada, sin costo alguno, a deducir y retener, del sueldo de sus trabajadores, la suma que éstos adeuden a las cooperativas, siempre que los trabajadores sean asociados de las cooperativas acreedoras y que la deuda y causa conste en libranza, pagaré o cualquier otro documento.

14.2. Creación de fondos para sostener entes cooperativos de integración y ayuda a Cooperativas

La creación de fondos para sostener entes cooperativos de integración y ayuda a cooperativas, la encontramos particularmente en PANAMA. La reciente normativa panameña creó los fondos de integración y el fondo especial de fomento y desarrollo del cooperativismo, por medio de los artículos 75 y 76, cuyo contenido transcribimos:

Artículo 75. El fondo de integración será entregado por las cooperativas de primer y segundo grado, a la confederación de cooperativas, para el fomento o funcionamiento, educación y asistencia técnica.

Parágrafo transitorio hasta tanto la confederación de cooperativas se constituya, el fondo de integración será entregado al Consejo Nacional de Cooperativas (CONALCOOP).

Artículo 76. El fondo especial para el fomento y desarrollo del cooperativismo, es un recurso económico que las cooperativas de primer y segundo grado entregarán al IPACOOP, para apoyar programas específicos de fomento y desarrollo cooperativo.

Este fondo será administrado por un comité integrado así: un representante del IPACOOP, un representante del Contralor de la República y un representante del CONALCOOP. Hasta tanto la confederación se constituya, este fondo sólo podrá emplearse en programas de capacitación, educación y asistencia técnica, se prohíbe el empleo de sus recursos para el nombramiento de personal administrativo. 


\subsection{Privilegio de cobro a favor de la Cooperativa}

Las normas de trato preferente se repiten en la legislación centroamericana, como un leiv motiv, y COSTA RICA no queda fuera de esa reiteración, cuando encontramos en el artículo 70, segundo párrafo, las disposiciones especiales al respecto.

Los certificados de aportación, depósitos, participaciones o derechos de cualquier clase que correspondan a los asociados de una cooperativa, quedan vinculados preferentemente y desde su origen, a favor de ésta, como garantía de la obligación u obligaciones que aquéllos pudieran llegar a tener con la asociación.

Otro ejemplo del trato preferencial, son los límites a la embargabilidad del capital social, que es una norma general para todas las personas jurídicas de responsabilidad limitada, y cuyo contenido fue trasladado también a la normativa cooperativa. Seguimos con el ejemplo costarricense, a través del siguiente artículo:

Artículo 71. Los certificados de aportación de los asociados sólo podrán ser embargados por los acreedores de la cooperativa, dentro de los límites del capital y responsabilidad sociales. Dichos acreedores podrán ejercer los derechos de la cooperativa, relativos a los aportes de capital no pagados, siempre que fueran exigibles y necesarios para el pago de las deudas sociales. Este privilegio otorgado a los referidos acreedores no excluye los derechos preferentes de la cooperativa, cuando ésta tenga que proceder contra los asociados, excepto en las cooperativas de autogestión que se regirán por lo que se establece en el capítulo XI.

En Guatemala y El Salvador también está prevista la posibilidad de compensación de deudas de los socios con su cooperativa y la sujeción preferente de componentes de la propiedad cooperativa individual —sumas de los socios-.

\section{GUATEMALA:}

Artículo 124. Las cooperativas con conocimiento de sus afiliados pueden retener aportaciones, depósitos y cualesquiera otros valores de los cooperativistas y con los valores retenidos cubrir obligaciones del afiliado a la cooperativas.

Artículo 125. Las aportaciones, depósitos, participaciones y derechos de cualquier clase que correspondan a los cooperativistas, 
quedan sujetos preferentemente a favor de la cooperativas por las obligaciones que aquéllos hayan contraído a favor de éstas.

\section{EL SALVADOR:}

Artículo 46. Cuando el asociado adeude, parte de las aportaciones que haya suscrito los excedentes e intereses que le correspondan por los aportes de capital que hubiere pagado serán aplicados hasta donde alcancen, a cubrir el saldo exigible.

Artículo 47. Las asociaciones cooperativas gozarán de prelación, y derechos de retención, sobre excedentes, intereses, aportaciones, y depósitos que los asociados tengan en ellas; los fondos correspondientes podrán ser aplicados, en ese orden hasta donde alcancen a extinguir otras deudas exigibles a cargo de éstos por obligaciones voluntarias o legales a favor de aquéllas.

Los acreedores personales de los asociados, no pueden embargar más que los excedentes e intereses que le correspondan a éstos y a la parte del capital a que tengan derecho en caso de liquidación, para cuando ésta se efectúe.

\subsection{Formas de financiamiento a través de la integración cooperativa}

En PANAMA al igual que en los otros países centroamericanos está prevista la formación de entes cooperativos de integración, generalmente denominados uniones y federaciones cooperativas, cuya función principal es ofrecer servicios que faciliten el giro económico de las cooperativas que forman parte, así como establecer mecanismos de representanción y defensa.

En ese país, encontramos plasmadas las actividades mencionadas en los siguientes artículos:

Artículo 97. Las cooperativas y las federaciones, cuando lo estimen conveniente, con previa autorización del IPACOOP, podrán unirse para crear organizaciones de seguros $u$ otras actividades y ofrecer estos servicios, que se regirán en sus aspectos técnicos, conforme a las normas generalmente aceptadas.

Artículo 111. Las donaciones, legados, subsidios y todo otro recurso análogo que reciban las asociaciones cooperativas por parte de cualquier persona natural o jurídica, estarán exentos del pago del impuesto sobre la renta y serán deducibles, al afecto, para quien lo efectúe. 


\section{HONDURAS:}

Este país se encuentra inmerso en un plan de reconstrucción debido a los efectos nocivos del huracán Micht. De tal modo, que el cooperativismo hondureño ha sido tomado en cuenta como una herramienta para permitir la democratización de la economía así como el medio para el acceso de recursos productivos, de los segmentos de población que forman pequeñas y medianas empresas. Al respecto citamos un interesante informe sobre esta situación y recomendamos su lectura para efectos de tener una idea más clara de la situación en que se encuentra inmerso el cooperativismo hondureño. ${ }^{22}$

22 Verlo en el informe presentado por el Lic. Fernando E. García denominado Plan de reconstrucción y desarrollo del Sector cooperativo de Honduras para contrarrestar los efectos del huracán y tormenta tropical Micht, Tegucigalpa, Honduras, marzo 1999, bajo el auspicio de la Confederación Hondureña de Cooperativas, Alianza Cooperativa Internacional, Foro nacional de convergencia, Centro cooperativo sueco y la Real Sociedad de Noruega. Citamos algunos párrafos significativos: 10.11 En cuanto al proceso productivo nacional ya se ha señalado el gran impacto que tienen en la generación del Producto Interno Bruto (PIB) y de empleo permanente directo e indirecto. Un elemento fundamental es su contribución a democratizar la economía, mediante el acceso a los activos productivos por parte de miles de cooperativistas que si no fuera por este tipo de organizaciones su condición sería estrictamente de asalariados y con un nivel de vida, aún más bajo. Sin embargo se señala con preocupación el impacto que pueda tener la política de apertura comercial, tanto en su expresión de integración regional, como de «inserción en la economía internacional», en los diferentes tipos de empresas de Movimiento. Es importante señalar que las diferentes organizaciones miembros de la comisión, tienen consciencia de las modificaciones del entorno, tanto a nivel nacional como regional e internacional, lo cual demanda un fuerte proceso de reconversión y modernización productiva de las empresas miembros, como única alternativa para poder ser competitivos en los diferentes mercados.

10.12 Como características de las empresas del Movimiento Cooperativo se puede señalar el que su desarrollo se realiza en un marco jurídico con algunas limitaciones y niveles de obsolecensia y que han sobrevivido al margen de un régimen jurídico que les otorgue beneficios especiales de significación. Su constitución es legal y existen Convenios Internacionales que protegen y promueven su desarrollo, así como organizaciones subregionales, regionales e internacionales que prestan servicios de apoyo a las mismas.

10.13 En cuanto a sus características productivas se puede señalar que se realizan esfuerzos orientados a superar sus niveles tecnológicos actuales, requieren para tal propósito realizar inversiones adicionales para las cuales no se cuenta con la disponibilidad de recursos en condiciones apropiadas. Se señala como dichas empresas utilizan, fundamentalmente, materia prima nacional y generan empleo en los sectores poblacionales de menores recursos del país. En cuanto a comercialización se refiere es necesario señalar que aún cuando se han realizado avances significativos por establecer mecanismos ágiles y modernos, sin embargo los niveles de concreción, desarrollo y utilización de los mismos es limitado. 
Artículo 113. Los ministerios y entidades de fomento o desarrollo darán preferencia a las cooperativas, en lo concerniente a la asistencia técnica, agropecuaria, crediticia o comercialización de productos.

\subsection{Crédito a favor de las Cooperativas}

Las cooperativas pueden tener diferentes fuentes de financiamiento, que algunos casos se da a través de las facilidades $u$ opciones previstas en la legislación especial, en la cual se establece la ayuda gubernamental.

En PANAMA como Guatemala están bien indicadas esas posibilidades en diferentes artículos, que no deja por fuera todo el gobierno central ni local, como el caso de las municipalidades:

Artículo 112. Los ministerios, entidades autónomas y semiautónomas así como los municipios, darán preferencia y facilidades a la adjudicación en favor de las cooperativas, de aquellas parcelas de terreno que resulten técnicamente apropiadas para el desarrollo de sus actividades. Así mismo, las asociaciones cooperativas podrán comprar o arrendar bienes pertenecientes al Estado y a las entidades autónomas y semiautónomas, sin necesidad de concurrir a licitación pública o a concurso.

Artículo 113. Los ministerios y entidades de fomento o desarrollo, darán preferencia a las cooperativas, en lo concerniente a la asistencia técnica, agropecuaria, crediticia o comercialización de productos.

10.14 En cuanto a las características administrativas y gerenciales es oportuno indicar que tanto la Confederación como las Federaciones realizan, en el marco de sus posibilidades reales, esfuerzos dirigidos a obtener niveles gerenciales y administrativos que respondan a ese entorno dinámico y cambiante que exige como mínimo una Planificación Estratégica y una Administración Financiera y Contable sencilla, operativa y que responda, por un lado a los niveles de desarrollo de los diferentes tipos de empresas cooperativistas, y por otro, a los requerimientos de los organismos de prestación de servicios financieros y no financieros (capacitación, asistencia técnica y otros).

10.15 En materia financiera se puede señalar que normalmente no tienen acceso al crédito del sistema formal o convencional supervisado y que realizan esfuerzos por accesar a otras fuentes de financiamiento de Instituciones no convencionales o establecer sus propias instituciones especializadas. En general se señala la poca disposición de garantías y que más que un problema de tasa de interés, su problema básico es el acceso al crédito oportuno y en plazos y condiciones por ellos. 
Artículo 114. El Ministerio de Vivienda, el Banco Hipotecario Nacional, la Caja de Ahorros, el Banco Nacional, la Caja de Seguro Social y cualquier otro organismo estatal, darán facilidades de crédito y asistencia técnica a las cooperativas.

Otro ejemplo es NICARAGUA, donde se establece la obligación para el Departamento de promoción del cooperativismo.

\section{CAPITULO I}

Artículo 20. El Departamento de Promoción del Cooperativismo, tendrá las siguientes funciones y atribuciones:

a) Iniciar, promover y dirigir la organización de todo tipo de cooperativas y prestarles asesoramiento y asistencia en la medida de los recursos del Ministerio.

b) Estructurar planes de fomento y desarrollo cooperativista en coordinación con el Banco Nacional de Nicaragua, Instituto Agrario, Banco Nicaragüense de la Vivienda, Ministerio de Agricultura y Ganadería y Oficina de Planificación del Consejo Nacional de Economía, así como con los organismos de integración y demás instituciones estatales, municipales y particulares, interesadas en estas actividades, a fin de obtener la integración y unidad del movimiento cooperativista y de que éste se enmarque dentro de los programas de desarrollo socioeconómico del país.

\section{GUATEMALA:}

\section{Artículo 25. Asistencia financiera}

El Estado establecerá una política financiera de apoyo al movimiento cooperativo, a tal efecto situará en el Banco de Guatemala los fondos necesarios para financiar parcial o totalmente los programas que se estimen de mayor prioridad. Dichos fondos serán canalizados a través del sistema bancario nacional.

El crédito puede ser bancario, público o privado. Puede provenir de alguna agencia de cooperación que funciona en la región centroamericana; de la autoridad de aplicación, o bien, de la propia decisión de los socios.

La ayuda estatal generalmente está unida a los objetivos y políticas del organismo denominado la autoridad de aplicación ${ }^{23}$; en las leyes de creación de estos entes se encuentran definidos tales fines.

23 Ver Proyecto de Ley marco para cooperativas de América. 
También existen diversos programas de ayuda estatal que apoyan financieramente a las cooperativas, de acuerdo con el giro económico que realizan. Los programas de apoyo.

Artículo 155. El Instituto Nacional de Fomento Cooperativo, INFOCOOP, tiene como finalidad: fomentar, promover, financiar, divulgar y apoyar el cooperativismo en todos los niveles, propiciando las condiciones requeridas y los elementos indispensables, a una mayor y efectiva participación de la población del país, en el desenvolvimiento de la actividad económico-social que simultáneamente contribuya a: crear mejores condiciones de vida para los habitantes de escasos recursos, realizar una verdadera promoción del hombre costarricense y fortalecer la cultura democrática nacional.

Artículo 157. Para el cumplimiento de sus propósitos el Instituto Nacional de fomento Cooperativo tendrá las siguientes funciones y atribuciones de carácter general:

d) Conceder crédito a las asociaciones cooperativas en condiciones y proporciones especialmente favorables al adecuado desarrollo de sus actividades, percibiendo por ello, como máximo, los tipos de interés autorizados por el Sistema Bancario Nacional;

e) Servir a las cooperativas y a los organismos integrativos como agente financiero y avalar cuando sea necesario y conveniente, los préstamos que aquellos contraten con entidades financieras nacionales o extranjeras.

f) Promover y en caso necesario participar, en la formación de empresas patrimoniales de interés público, entre las cooperativas, las municipalidades y entes estatales, conjunta o separadamente, tratando siempre de que en forma gradual y coordinada, los certificados de aportación pasen a manos de los cooperadores naturales;

g) Obtener empréstitos nacionales y extranjeros con instituciones públicas, y gestionar la participación económica de las entidades estatales que corresponda, para el mejor desarrollo del movimiento cooperativo nacional;

h) Participar como asociado de las cooperativas cuando las circunstancias así lo demanden, previa solicitud de la asamblea de la cooperativa respectiva y estudio de factibilidad del INFOCOOP para determinar la importancia del proyecto. En aquellas cooperativas que tengan menos de cuatro años de existencia y en las cuales el aporte de capital del Instituto sea superior a un $60 \%$ del capital social de la cooperativa, el Instituto podrá nombrar y remover al gerente. Esta designación tendrá un plazo máximo de cinco años. 


\section{A modo de conclusión}

Gracias a la iniciativa de la Directiva de la Asociación Internacional de Derecho Cooperativo podemos avanzar en el análisis del Derecho Comparado Cooperativo. Pasamos de un análisis meramente normativo a ver las instituciones jurídicas. Para lograr tal objetivo se necesita mucho trabajo y conciencia entre los miembros de la Asociación. Existen múltiples formas de llegar a la legislación cooperativa del istmo centroamericano: COLAC, el Consejo de Cooperativas de Uruguay ofrecen sus bases de datos. Lo difícil es llegar a conocer realmente cómo se está aplicando la legislación en cada país. Esta es una tarea que he venido planteando a varios colegas en Latinoamérica, espero que podamos avanzar más en el conocimiento de la efectividad de las normas en cada país centroamericano, a través de una mayor unión de nuestros esfuerzos en esta parte del mundo, junto con los de los y las colegas de la Asociación, en Bilbao.

Quedamos en deuda con un planteamiento que estudie el financiamiento externo de las cooperativas de la región centroamericana. Financiamiento que está fundamentado en el desarrollo de programas para fortalecer la mediana y pequeña empresa. Dejamos planteado que gracias a la labor de integración de la Confederación de Cooperativas de Centroamérica y el Caribe, existen varios entes y agencias gubernamentales que apoyan al cooperativismo de la región. Sólo por mencionarlos, hincamos con la $\mathrm{ACl}$ para las Américas, con sede en San José, Costa Rica. También están el Centro cooperativo sueco que apoyó el Programa de mejoramiento de la calidad cooperativa; la Iniciativa costarricense para la competitividad internacional, de origen canadiense, que apoyó el Programa de Clusters como herramienta para la competitividad cooperativa, el Fondo contravalor Costa Rica. Canadá, que apoyó el programa de investigación de la CCC-CA para ejecución del II Censo Cooperativo de Costa Rica: el Fondo de igualdad de género de ACDI, Canadá, apoyó el inicio de un proyecto de Modelos productivos con perspectiva de género y la Embajada Real de los Países Bajos que apoyó la extensión del programa de Reconversión de Honduras y Nicaragua. ${ }^{24}$

24 Memoria de la Confederación de Cooperativas del Caribe y C.A. 2000-2001. 
También está pendiente el aspecto del financiamiento externo al movimiento cooperativo proveniente de las entidades del Sector de Economía social, definido básicamente por medio de alianzas de los sectores que componen el Sector.

\section{Bibliografía básica}

ARAnZADI, Dionisio, Cooperativismo industrial como sistema, empresa y experiencia, Universidad de Deusto, Bilbao, España, 1976.

Memoria de la Confederación de Cooperativas del Caribe y C.A. 2000-2001.

COSTA RICA, Ley de Asociaciones cooperativas y creación del Instituto Nacional de Fomento cooperativo N. 4179 de 22 de agosto de 1968 y sus reformas.

- Ley de Regulación de la Actividad de Intermediación Financiera de las Organizaciones Cooperativas, la cual rige a partir del 24 de mayo de 1994.

El Salvador, Ley No. 17 del 1. ${ }^{\circ}$ de mayo de 1977 - Régimen Especial de las Cooperativas

HonduRAs, Ley de Cooperativas, N. 65-87 de 30 abril de 1987.

Guatemala, Decreto número 82-78, Ley General de Cooperativas, Guatemala, 7 de diciembre de 1978.

Nicaragua, Decreto No. 1833, Ley General de Cooperativas.

-, Decreto número 82-78, Ley General de Cooperativas.

PanAmá, Ley N. 17 de 1 mayo de 1997. Régimen especial de las cooperativas. 